\title{
PERMUDAAN ALAMI HUTAN DI SATUAN PENGELOLAAN TAMAN NASIONAL (SPTN) WILAYAH III KUALA PENET TAMAN NASIONAL WAY KAMBAS
}

\section{(NATURAL REGENERATION FOREST NATIONAL PARK MANAGEMENT UNIT (NPMU) REGION III KUALA PENET WAY KAMBAS NATIONAL PARK)}

\author{
Dwi Rahayu Damayanti, Afif Bintoro, dan Trio Santoso \\ Jurusan Kehutanan Fakultas Pertanian Universitas Lampung \\ Jl. Soemantri Brojonegoro No.1 Bandar Lampung \\ E-mail: Dwirahayudamayanti@gmail.com \\ Phone: 082175291617
}

\begin{abstract}
ABSTRAK
Satuan Pengelolaan Taman Nasional (SPTN) Wilayah III Kuala Penet Resort Margahayu merupakan bagian dari Kawasan Taman Nasional Way Kambas (TNWK). SPTN Wilayah III Kuala Penet sebagai daerah penyangga TNWK yang terus dipertahankan agar tetap memiliki keanekaragaman jenis tumbuhan yang sangat tinggi dalam susunan struktur dan komposisi jenis tertentu. Penelitian ini bertujuan untuk mengetahui komposisi jenis, struktur tegakan, dan kondisi permudaan alam sebagai gambaran kinerja suksesi tegakan pada SPTN Wilayah III Kuala Penet. Penelitian dilakukan pada bulan Agustus hingga September 2015 dengan kegiatan analisis vegetasi menggunakan metode pengambilan sampel garis berpetak sebagai cara untuk mendapatkan data primer, berupa: spesies tegakan, jumlah spesies, diameter batang dan tinggi total pohon. Hasil penelitian menunjukkan bahwa terdapat 32 jenis tumbuhan pada kawasan SPTN Wilayah III Kuala Penet Resort Margahayu. Indeks Nilai Penting (INP), menunjukkan bahwa terdapat jenis tumbuhan yang paling dominan, yaitu berasan, kopen, puspa, sempu, sonokeling, dan tiga urat sedangkan jenis belimbingan, bungur, keteja, keruing, mahoni, tutup, dan waru memiliki tingkat penguasaan rendah diantara 32 jenis tumbuhan yang ditemukan dalam penelitian. Struktur tegakan secara horizontal menunjukkan bahwa secara umum tegakan didominansi oleh tumbuhan dengan diameter $<10$ $\mathrm{cm}$ dan semakin menurun untuk kelas diameter $10-<20 \mathrm{~cm}$ sampai $>60 \mathrm{~cm}$, sedangkan struktur tegakan vertikal menunjukkan bahwa tegakan didominansi oleh stratum $\mathrm{C}$ sebanyak 28 jenis, diikuti stratum D (22) jenis, stratum E (18) jenis, dan stratum B satu jenis. Kondisi permudaan alam di SPTN Wilayah III Kuala Penet Resort Margahayu menunjukkan kondisi hutan normal, karena tingkat kerapatan tegakan didominansi oleh fase semai, diikuti pancang, tiang, dan pohon dengan bentuk kurva menyerupai huruf "J" terbalik.
\end{abstract}

Kata kunci: Komposisi Jenis, Permudaan Alam, SPTN, Struktur Tegakan, TNWK

\section{ABSTRACT}

National Park Management Unit (SPTN) Region III Kuala Penet Resort Margahayu is part of the National Park Way Kambas (TNWK). SPTN Region III Kuala Penet as the buffer area TNWK are maintained to keep a diversity of plants is very high in the composition of the structure and composition of a certain type. This study aims to determine the species composition, stand structure and condition of natural regeneration as a performance snapshot succession of stands in Region III SPTN Kuala Penet. The study was conducted 
from August to September 2015 with the activities of the vegetation analysis using sampling methods terraced lines as a way to obtain primary data, such as: the species stands, the number of species, stem diameter and a height of trees. The results showed that there are 32 species in the region Region III SPTN Kuala Penet Resort Margahayu. Importance Value Index (IVI), shows that there are plant species that is most dominant, berasan, kopen, sempu, sonokeling and tiga urat, whereas the type belimbingan, bungur, keteja, keruing mahoni, tutup, and waru have low mastery level. Horizontal stand structure indicate that in general stands dominated by plants with a diameter $<10 \mathrm{~cm}$ and adiameter decreases to stand $10-<20$ $\mathrm{cm}$ to $>60 \mathrm{~cm}$. While the vertical stand structure indicate that the stratum $C$ stands were dominated by as many as 28 species, followed by stratum D (22) types, stratum E (18) types, and the stratum $B$ one types. The condition of Natural regeneration in SPTN Region III Kuala Penet Resort Margahayu showed that the condition of the forest was normal because the density was dominated by the seedling phase, followed by phases of saplings and poles with the curves shape resembles the letter "J" reversed.

Keywords: Assisted Natural Regeneration, Composition Type, SPTN, Stand Structure, TNWK

\section{PENDAHULUAN}

Taman Nasional Way Kambas (TNWK) adalah satu dari dua kawasan konservasi yang berbentuk Taman Nasional di Provinsi Lampung selain Taman Nasional Bukit Barisan Selatan (TNBBS). Ditetapkan melalui Surat Keputusan Menteri Kehutanan Nomor 670/Kpts-II/1999 tanggal 26 Agustus 1999, kawasan TNWK mempunyai luas lebih kurang 125.631,31 ha. Kawasan TNWK dalam bentuk alamiah aslinya mempunyai keanekaragaman jenis tumbuhan sangat tinggi dari berbagai tipe habitat yang luas tersebar di seluruh kawasan TNWK dengan berbagai tipe vegetasi.

Jenis-jenis tegakan yang dapat dijumpai adalah meranti (Shorea sp.), sempur (Dillenia excelsa), merawan (Hopea sp.), minyak (Dipterocarpus retusus), merbau (Instia palembanica), jabon (Anthocepalus chinesis), dan puspa (Schima wallichii). Tipe vegetasi hutan rawa atau daerah yang selalu basah ditumbuhi oleh nibung (Oncosperma tigilaria), gelam (Melaleuca spp.), rotan (Calamus sp.), palem merah (Cytostachys lakka), rengas (Gluta renghas), dan jenis-jenis rumput rawa (Balai Taman Nasional Way Kambas, 2006).

Satuan Pengelolaan Taman Nasional (SPTN) Wilayah III Kuala Penet Resort Margahayu merupakan bagian dari TNWK yang mempunyai keanekaragaman jenis tumbuhan yang sangat tinggi dan beragam. Jenis-jenis tumbuhan yang ada di SPTN Wilayah III Kuala Penet Resort Margahayu diperlukan di dalam penelitian untuk mengetahui klasifikasi ilmiahnya serta informasi data yang sesuai dengan judul yaitu permudaan alam.

Permudaan alam hutan adalah peremajaan hutan secara alami yang komponennya terdiri dari tingkat semai, pancang dan tiang. Proses permudaan alam hutan merupakan aspek ekologi yang cukup besar peranannya terhadap pembentukan struktur tegakan hutan dan komposisi jenis tumbuhannya. Permudaan alam hutan di SPTN Wilayah III Kuala Penet Resort Margahayu tersusun atas struktur tegakan dan komposisi jenis. Untuk mengetahui kondisi tegakan serta keberlanjutan regenerasi permudaannya di zona pemanfaatan terbatas, yaitu dengan melihat struktur tegakan dan komposisi jenis yang ada di SPTN Wilayah III Kuala Penet Resort Margahayu. Tujuan dari penelitian ini adalah untuk mengetahui komposisi jenis di SPTN Wilayah III Kuala Penet Resort Margahayu, struktur tegakan yang terdapat di SPTN Wilayah III Kuala Penet Resort Margahayu dan kondisi permudaan hutan alam di SPTN Wilayah III Kuala Penet Resort Margahayu. 


\section{METODE PENELITIAN}

\section{Lokasi dan Waktu Penelitian}

Penelitian ini dilakukan pada bulan Agustus sampai dengan September 2015 di SPTN Wilayah III Kuala Penet Resort Margahayu TNWK.

Peralatan yang digunakan dalam penelitian adalah kompas, kamera, tali plastik, patok kayu, hagameter, meteran, dan alat tulis. Bahan yang dipergunakan sebagai objek penelitian ini berupa permudaan hutan yang ada di SPTN Wilayah III Kuala Penet Resort Margahayu di zona pemanfaatan TNWK seluas 361 ha. Sampel penelitian terdiri dari plot untuk penelitian masing-masing fase pertumbuhan.

\section{Data yang dikumpulkan}

Jenis data yang digunakan dalam penelitian ini adalah data primer dan data sekunder. Data primer berupa spesies tegakan, jumlah spesies, diameter batang (dbh), dan tinggi total pohon.

Data sekunder pada penelitian ini meliputi data penunjang yang berupa peta TNWK, status kawasan, deskripsi kawasan, potensi flora, fauna, tanah, topografi, hidrologi, iklim, dan literatur yang berhubungan dengan penelitian ini. Data primer dalam penelitian ini diperoleh dengan cara observasi. Observasi dilakukan di zona pemanfaatan Resort Margahayu. Penelitian dilakukan dengan analisis vegetasi menggunakan metode garis berpetak yaitu dengan cara melompati satu atau lebih petak-petak pada jarak tertentu dengan jarak yang sama. Luas sampel yang diambil sebesar 361 ha dengan intensitas sampling 0,5\% yang terdiri dari 45 petak ukur, untuk penelitian tiap fase pertumbuhan

\section{Analisis Data}

\section{Komposisi dan Tingkat Penguasaan Spesies}

Untuk menganalisis komposisi dan tingkat penguasaan spesies dilakukan penghitungan dengan rumus-rumus sebagai berikut (Soerianegara dan Indrawan, 1998).

a. Kerapatan

Kerapatan (K) jumlah individu per unit luas atau per unit volume. Penghitungan kerapatan dapat diketahui berdasarkan rumus berikut.

$$
\begin{aligned}
& \mathrm{K}_{\mathrm{i}}=\text { Jumlah individu untuk spesies ke - i } \\
& \text { Luas seluruh petak contoh } \\
& \mathrm{KR}_{\mathrm{i}}=\text { Kerapatan spesies } \mathrm{k}-\mathrm{i} \times 100 \% \\
& \text { Kerapatan seluruh spesies }
\end{aligned}
$$

b. Frekuensi

Penghitungan frekuensi setiap jenis tumbuhan dapat diketahui dengan menggunakan rumus sebagai berikut.

$\mathrm{F}_{\mathrm{i}}=\underline{\text { Jumlah petak contoh ditemukan suatu spesies } \mathrm{ke}-\mathrm{i}}$

$$
\text { Jumlah seluruh petak contoh }
$$

$$
\mathrm{FR}_{\mathrm{i}}=\frac{\text { Frekuensi spesies ke }-\mathrm{i}}{\text { Frekuensi seluruh petak contoh }} \times 100 \%
$$

c. Luas penutupan (C)

Penghitungan luas penutupan setiap jenis tumbuhan

$\mathrm{C}_{\mathrm{i}}=$ Total luas basal area spesies ke $-\mathrm{i}$

Luas seluruh petak contoh

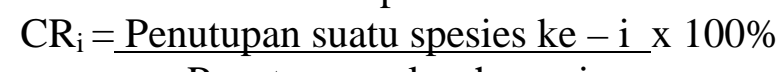

Penutupan seluruh spesies

d. Indeks Nilai Penting

Penghitungan INP untuk fase pohon, tiang, dan pancang, digunakan rumus: 
$\mathrm{INP}=\mathrm{KR}+\mathrm{FR}+\mathrm{CR}$

Sedangkan penghitungan INP untuk fase semai digunakan rumus:

$\mathrm{INP}=\mathrm{KR}+\mathrm{FR}$

Tingkat penguasaan spesies diklasifikasikan menjadi 3 yaitu tinggi/dominan, sedang, rendah/tidak dominan. Penghitungan tingkat penguasaan spesies digunakan rumus sebagai berikut: Interval klas $(\mathrm{I})=\underline{\text { INP tertinggi }-\mathrm{INP} \text { terendah }}$

$$
3
$$

Keterangan:

Tinggi (dominan) jika INP> (INP terendah $+2 \mathrm{I})$

Sedang jika INP $=($ INP terendah $+\mathrm{I})-($ INP terendah $+2 \mathrm{I})$

Rendah (tidak dominan) jika INP $<($ INP terendah + I).

\section{HASIL DAN PEMBAHASAN}

\section{Hasil}

\section{Komposisi dan tingkat penguasaan spesies}

Hasil penelitian menunjukan bahwa terdapat 32 spesies yang ditemukan di SPTN Wilayah III Kuala Penet Resort Margahayu. Dengan berbagai keragaman INP per fase, dan tingkat penguasaan spesies. Komposisi dan tingkat penguasaan spesies di SPTN Wilayah III Kuala Penet Resort Margahayu, selengkapnya dapat dilihat pada Tabel 1.

Tabel 1. Komposisi dan tingkat penguasaan spesies di SPTN Wilayah III Kuala Penet Resort Margahayu

\begin{tabular}{|c|c|c|c|c|c|c|c|}
\hline \multirow[t]{2}{*}{ No } & \multirow[t]{2}{*}{ Nama Ilmiah } & \multirow{2}{*}{$\begin{array}{l}\text { Spesies } \\
\text { Tumbuhan }\end{array}$} & \multicolumn{4}{|c|}{ INP Per Fase } & \multirow{2}{*}{$\begin{array}{l}\text { Tingkat } \\
\text { Penguasaan }\end{array}$} \\
\hline & & & Semai & Pancang & Tiang & Pohon & \\
\hline 1 & Acacia auriculiformis & Akasia & - & - & - & 11,30 & Rendah \\
\hline 2 & Adina polycephola & Kenangi & - & - & 2,27 & 7,51 & Rendah \\
\hline 3 & Anthocephalus cadamba & Jabon & 8,22 & 22,52 & 3,73 & - & Rendah \\
\hline 4 & Aprosa aquila & Plangas & 0,40 & 7,64 & 13,86 & 4,50 & Rendah \\
\hline 5 & Bridelia monoica & Kelandri & 1,27 & 17,17 & 39,85 & 8,46 & Rendah \\
\hline 6 & Cachosus alstuans & Kopen & 67,06 & 29,60 & 7,49 & - & Tinggi \\
\hline 7 & Canarium ovatum & Kenaren & - & - & 5,56 & - & Rendah \\
\hline 8 & Cerbiamemum inkrs & Tiga urat & 4,98 & 67,22 & 16,63 & - & Tinggi \\
\hline 9 & Cinnamomum parthenoxylon & Keteja & - & 3,15 & - & - & Rendah \\
\hline 10 & Clausena excavate & Tikusan & 20,64 & 1,64 & - & - & Rendah \\
\hline 11 & Dalbergia latifolia & Sonokeling & 1,66 & 19,77 & 99,45 & 98,01 & Tinggi \\
\hline 12 & Dillenia exelsa & Sempu & - & 39,09 & 7,61 & 37,09 & Tinggi \\
\hline 13 & Dipterocarpus grasilis & Kruing & - & 3,70 & - & - & Rendah \\
\hline 14 & Eugenia sp. & Jambuan & 4,11 & 4,12 & - & - & Rendah \\
\hline 15 & Flacourtia rukam & Rukem & - & 2,04 & 2,24 & 3,31 & Rendah \\
\hline 16 & Gluta renghas & Rengas & - & 0,98 & 18,18 & 9,59 & Rendah \\
\hline 17 & Hibiscus tiliaceus & Waru & 0,40 & - & - & 2,94 & Rendah \\
\hline 18 & Koompassia excelsa & Menggris & - & - & - & 8,70 & Rendah \\
\hline 19 & Lagestroemia speciosa & Bungur & - & - & - & 3,26 & Rendah \\
\hline 20 & Macaranga tanarius & Tutup & - & - & 2,04 & - & Rendah \\
\hline 21 & Microscos paniculata & Deluak & 2,93 & - & 4,28 & - & Rendah \\
\hline 22 & Nephelium eriopetalum & Rambutan hutan & 2,06 & - & 2,17 & 25,67 & Tinggi \\
\hline 23 & Peronema canescens & Sungkai & - & 6,12 & - & - & Rendah \\
\hline 24 & Planchonia valida & Kutat & - & - & 2,50 & 6,42 & Rendah \\
\hline 25 & Planconella nitida & Karetan & - & 0,98 & 11,79 & 8,59 & Rendah \\
\hline 26 & Quercus sumatranus & Parutan & 7,04 & 3,33 & - & 3,62 & Rendah \\
\hline 27 & Sarcothera sp. & Belimbingan & 2,45 & - & - & - & Rendah \\
\hline 28 & Schima wallichii & Puspa & 31,79 & 59,07 & 35,68 & 25,16 & Tinggi \\
\hline
\end{tabular}


Tabel 1. (Lanjutan)

\begin{tabular}{|c|c|c|c|c|c|c|c|}
\hline \multirow[t]{2}{*}{ No } & \multirow[t]{2}{*}{ Nama Ilmiah } & \multirow{2}{*}{$\begin{array}{l}\text { Spesies } \\
\text { Tumbuhan }\end{array}$} & \multicolumn{4}{|c|}{ INP Per Fase } & \multirow{2}{*}{$\begin{array}{l}\text { Tingkat } \\
\text { Penguasaan }\end{array}$} \\
\hline & & & Semai & Pancang & Tiang & Pohon & \\
\hline 29 & Symplocos stenosepala & Berasan & 44,21 & 38,97 & 15,20 & 2,83 & Tinggi \\
\hline 30 & Swietenia mahagoni & Mahoni & 0,40 & - & - & - & Rendah \\
\hline 31 & Terminalia bellirica & Joho & & - & - & 12,52 & Rendah \\
\hline \multirow[t]{2}{*}{32} & Vitex pubescens & Laban & 0,40 & 2,00 & 9,49 & 11,7 & Rendah \\
\hline & Total & & 200 & 300 & 300 & 300 & \\
\hline
\end{tabular}

Sumber: Data primer, 2015.

Keterangan: Tingkat penguasaan spesies rendah : INP $<18,31$

Tingkat penguasaan spesies sedang : INP 18,31-18,41

Tingkat penguasaan spesies tinggi: INP> 18,41

Berdasarkan Tabel 1 diketahui bahwa sebagian besar tingkat penguasaan spesies tumbuhan di SPTN Wilayah III Kuala Penet Resort Margahayu tergolong rendah, namun ada beberapa spesies yang tergolong tingkat penguasaan spesies tinggi yaitu puspa dan sonokeling dengan kerapatan masing-masing sebesar 155 batang/ha dan 92 batang/ha yang memiliki INP sebesar $149,35 \%$ dan $220,97 \%$.

\section{Struktur Tegakan}

\section{a. Struktur tegakan horizontal}

Struktur tegakan dibuat dengan membuat hubungan antara kelas diameter setinggi dada (cm) dengan kerapatan pohon (jumlah pohon per hektar). Kerapatan pohon (jumlah pohon per hektar) diletakkan pada sumbu y, sedangkan kelas diameter sebagai absis. Jumlah pohon dalam setiap kelas diameter dapat dilihat pada Gambar 5.

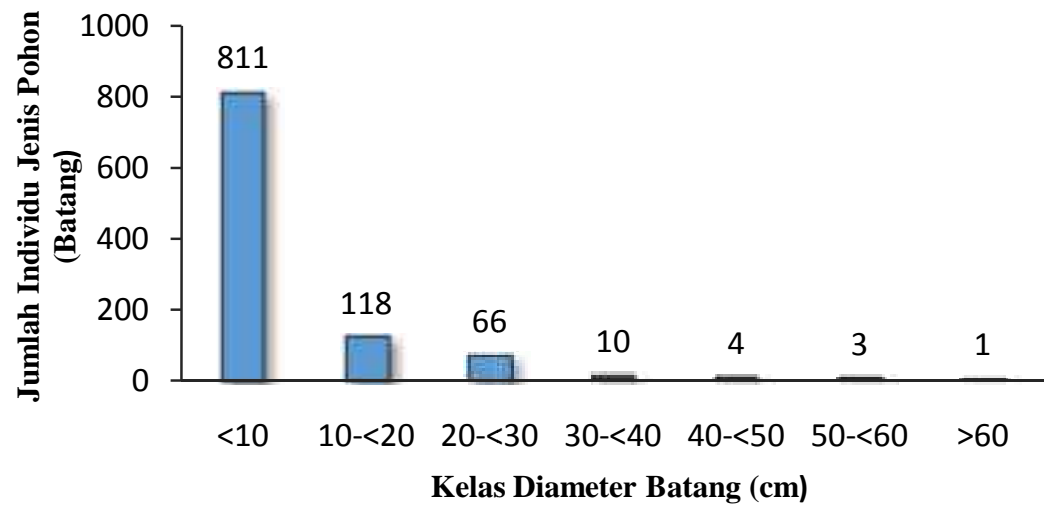

Gambar 5. Struktur tegakan berdasarkan hubungan antara kelas diameter dengan jumlah pohon di lokasi penelitian.

Berdasarkan grafik diatas diketahui bahwa jumlah pohon yang paling banyak terdapat pada kelas diameter $<10 \mathrm{~cm}$ dengan jumlah 811 kemudian terjadi penurunan secara drastis pada kelas diameter selanjutnya yaitu kelas diameter $10-<20 \mathrm{~cm}$ dengan jumlah 118 . Jumlah pohon pada diameter $20-<30 \mathrm{~cm}$ berjumlah 66 , pada diameter $30-<40 \mathrm{~cm}$ berjumlah 10 , pada diameter $40-<50 \mathrm{~cm}$ berjumlah 4 , pada diameter $50-<60 \mathrm{~cm}$ berjumlah 3 . Jumlah pohon paling sedikit terdapat pada kelas diameter diatas $60 \mathrm{~cm}$ dengan jumlah 1. 


\section{b. Struktur tegakan vertikal}

Struktur tegakan memiliki jumlah spesies pada setiap stratum di SPTN Wilayah III Kuala Penet Resort Margahayu. Jumlah spesies pada setiap stratum selengkapnya disajikan pada Tabel 2.

Tabel 2. Jumlah spesies pada setiap stratum di SPTN Wilayah III Kuala Penet Resort Margahayu

\begin{tabular}{|c|c|c|c|}
\hline No & Stratum & Tinggi (m) & Spesies Penyusunnya \\
\hline 1 & A & $33-30$ & - \\
\hline 2 & B & $20-30$ & Joho. \\
\hline 3 & C & $4-20$ & $\begin{array}{l}\text { Sonokeling, waru, kelandri, rengas, } \\
\text { sempu, parutan, kenangi, puspa, bungur, } \\
\text { rambutan, karetan, laban, akasia, rukem, } \\
\text { plangas, kutat, menggris, kopen, berasan, } \\
\text { sungkai, tiga urat, tikusan, jabon, deluak, } \\
\text { tutup, kruing, kenaren, joho. }\end{array}$ \\
\hline 4 & D & $1-4$ & $\begin{array}{l}\text { Kopen, tikusan, kruing, puspa, keteja, } \\
\text { kelandri,berasan, sonokeling, laban, } \\
\text { sungkai, jabon, tiga urat, akasia, } \\
\text { jambuan, kutat, rukem, sempu, karetan, } \\
\text { parutan, rengas, plangas, deluak. }\end{array}$ \\
\hline 5 & $\mathrm{E}$ & $0,4-1$ & $\begin{array}{l}\text { Tikusan, kopen, deluak, kelandri, puspa, } \\
\text { berasan, belimbingan, laban, rambutan } \\
\text { hutan, tiga urat, jabon, mahoni, plangas, } \\
\text { jambuan, sungkai, parutan, deluak, waru. }\end{array}$ \\
\hline
\end{tabular}

Sumber: Data primer, 2015.

Berdasarkan Tabel 2 diketahui bahwa stratum $\mathrm{C}$ memiliki spesies paling banyak dengan jumlah 28, diikuti stratum D memiliki spesies dengan jumlah 22, kemudian stratum $\mathrm{E}$ memiliki spesies dengan jumlah 18, dan stratum B memiliki spesies terkecil dengan jumlah 1 sedangkan pada stratum A tidak memiliki spesies. Grafik perbandingan jumlah spesies pada setiap stratum dapat dilihat pada Gambar 6.

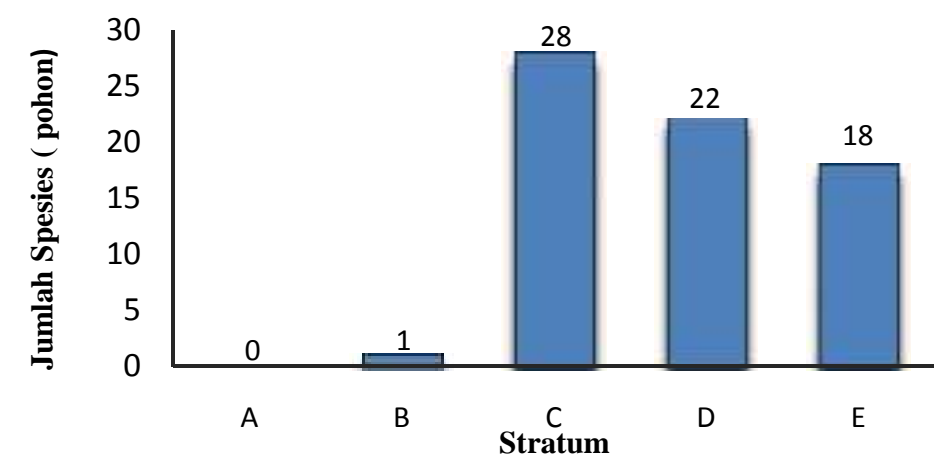

Gambar 6. Jumlah spesies pada setiap stratum di SPTN Wilayah III Kuala Penet Resort Margahayu.

\section{Permudaan Alam}

Permudaan alam di SPTN Wilayah III Kuala Penet Resort Margahayu, TNWK dapat dilihat pada kerapatan tegakan setiap fase pertumbuhannya pada Tabel 3.

Tabel 3. Kerapatan tegakan pada setiap fase pertumbuhan di SPTN Wilayah III Kuala Penet Resort Margahayu 


\begin{tabular}{|c|c|c|c|c|c|c|}
\hline \multirow[t]{2}{*}{ No } & \multirow[t]{2}{*}{ Nama Ilmiah } & \multirow{2}{*}{$\begin{array}{l}\text { Spesies } \\
\text { Tumbuhan }\end{array}$} & \multicolumn{4}{|c|}{ Kerapatan tiap fase (batang/ha) } \\
\hline & & & Semai & Pancang & Tiang & Pohon \\
\hline 1 & Acacia auriculiformis & Akasia & - & - & - & 2 \\
\hline 2 & Adina polycephola & Kenangi & - & - & 1 & 2 \\
\hline 3 & Anthocephalus cadamba & Jabon & 20 & 24 & 2 & - \\
\hline 4 & Aprosa aquila & Plangas & 1 & 2 & 6 & 1 \\
\hline 5 & Bridelia monoica & Kelandri & 3 & 19 & 17 & 3 \\
\hline 6 & Cachosus alstuans & Kopen & 161 & 32 & 3 & - \\
\hline 7 & Canarium ovatum & Kenaren & - & - & 2 & - \\
\hline 8 & Cerbiamemum inkrs & Tiga urat & 12 & 73 & 7 & - \\
\hline 9 & Cinnamomum parthenoxylon & Keteja & - & 1 & 5 & 3 \\
\hline 10 & Clausena excavate & Tikusan & 50 & 2 & - & - \\
\hline 11 & Dalbergia latifolia & Sonokeling & 4 & 18 & 40 & 30 \\
\hline 12 & Dillenia exelsa & Sempu & - & 10 & 3 & 11 \\
\hline 13 & Dipterocarpus grasilis & Kruing & - & 4 & - & - \\
\hline 14 & Eugenia sp. & Jambuan & 10 & 5 & - & - \\
\hline 15 & Flacourtia rukam & Rukem & - & 2 & 1 & 1 \\
\hline 16 & Gluta renghas & Rengas & - & 1 & 8 & 3 \\
\hline 17 & Hibiscus tiliaceus & Waru & 1 & - & - & 1 \\
\hline 18 & Koompassia excelsa & Menggris & - & - & - & 1 \\
\hline 19 & Lagestroemia speciosa & Bungur & - & - & - & 1 \\
\hline 20 & Macaranga tanarius & Tutup & - & - & 1 & - \\
\hline 21 & Microscos paniculata & Deluak & 7 & - & 2 & - \\
\hline 22 & Nephelium eriopetalum & Rambutan hutan & 5 & - & 1 & 7 \\
\hline 23 & Peronema canescens & Sungkai & - & 7 & - & - \\
\hline 24 & Planchonia valida & Kutat & - & - & 1 & 1 \\
\hline 25 & Planconella nitida & Karetan & - & 1 & 5 & 3 \\
\hline 26 & Quercus sumatranus & Parutan & 17 & 3 & - & 1 \\
\hline 27 & Sarcothera sp. & Belimbingan & 6 & - & - & - \\
\hline 28 & Schima wallichii & Puspa & 77 & 55 & 15 & 8 \\
\hline 29 & Symplocos stenosepala & Berasan & 107 & 46 & 7 & 1 \\
\hline 30 & Swietenia mahagoni & Mahoni & 1 & - & - & - \\
\hline 31 & Terminalia bellirica & Joho & - & - & - & 2 \\
\hline \multirow[t]{2}{*}{32} & Vitex pubescens & Laban & 1 & 2 & 4 & 4 \\
\hline & Total & & 483 & 310 & 126 & 83 \\
\hline
\end{tabular}

Berdasarkan Tabel 3 diketahui bahwa spesies yang memiliki kerapatan spesies terbanyak dari fase semai adalah kopen dengan kerapatan 161 batang/ha. Kerapatan terbanyak pada fase pancang adalah tiga urat dengan kerapatan 73 batang/ha. Kerapatan terbanyak pada fase tiang adalah sonokeling dengan kerapatan sebesar 40 batang/ha. Kerapatan terbanyak pada fase pohon adalah sonokeling dengan kerapatan sebesar 30 batang/ha.

Perbandingan kerapatan tegakan pada setiap fase pertumbuhan dapat dilihat pada Gambar 7.

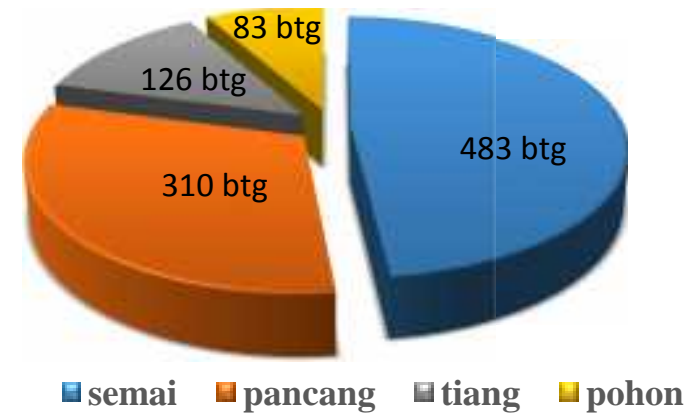

Gambar 7. Perbandingan kerapatan tegakan pada setiap fase pertumbuhan. 
Berdasarkan Gambar 7 diketahui bahwa kerapatan tegakan terbanyak pada setiap fase pertumbuhan dimiliki oleh fase semai yang memiliki jumlah spesies sebesar 483 batang, kemudian fase pancang 310 batang, fase tiang 126 batang, dan fase pohon 83 batang.

\section{Pembahasan}

\section{Komposisi dan Tingkat Penguasaan Jenis}

Komposisi dan tingkat penguasaan jenis sangat berkaitan dengan persaingan pertumbuhan. Menurut Richard (1966) istilah komposisi jenis digunakan untuk menyatakan keberadaan jenis-jenis pohon dalam hutan.

Berdasarkan hasil pengamatan di lapangan, diketahui bahwa jumlah jenis yang di temukan di SPTN Wilayah III Kuala Penet Resort Margahayu, pada tingkat semai sebanyak 17 spesies, sedangkan jumlah spesies yang ditemukan pada tingkat pancang, tiang, dan pohon yaitu sebanyak 19 spesies.

Komposisi dan tingkat penguasaan spesies dapat dilihat dari nilai Indeks Nilai Penting (INP) per fase. Spesies yang memiliki tingkat penguasaan tertinggi di SPTN Wilayah III Kuala Penet Resort Margahayu adalah berasan, kopen, puspa, sempu, sonokeling, dan tiga urat.

Tingkat penguasaan spesies menunjukkan spesies yang mendominansi dalam suatu komunitas tumbuhan. Dominansi menyatakan suatu spesies tumbuhan utama yang mempengaruhi dan melaksanakan kontrol terhadap komunitas. Dominansi suatu spesies tumbuhan dapat dilihat dari 1) jumlah spesies terbanyak, 2) ukuran diameter batangnya yang besar, 3) pertumbuhan yang dominan (Fachrul, 2007).

Menurut Odum (1994) jenis spesies yang mendominansi berarti memiliki kisaran lingkungan yang lebih luas dibandingkan dengan jenis yang lainnya, sehingga dengan kisaran toleransi yang luas terhadap faktor lingkungan menyebabkan suatu jenis tumbuhan akan memiliki sebaran yang luas.

Spesies yang mendominansi pada tingkat semai yaitu berasan, kopen, puspa dan tikusan. Pada tingkat pancang yaitu berasan, jabon, kopen, puspa, sempu, dan tiga urat. Pada tingkat tiang yaitu kelandri, puspa, dan sonokeling. Sedangkan pada tingkat pohon yaitu puspa, rambutan hutan, sempu, dan sonokeling.

Hal ini tidak jauh berbeda dengan penelitian yang dilakukan oleh Pratiwi (2014) di Zona Pemanfaatan Terbatas SPTN 1 Way Kanan. Spesies yang mendominansi pada fase semai adalah meranti tembaga, manggris, soka, dan plangas. Spesies Pada fase pancang adalah jabon, menggris, sempu air, dan plangas. Pada fase tiang adalah plangas, menggris, jabon dan sempu air. Sedangkan pada fase pohon adalah meranti tembaga, menggris, jabon, plangas, dan sempu air.

Dominannya spesies tersebut dikarenakan spesies-spesies tersebut berhasil memanfaatkan sebagian besar sumberdaya yang ada dibandingkan spesies-spesies yang lain. Spesies-spesies yang dominan seperti kopen, berasan, puspa, jabon, sempu, dan rambutan hutan merupakan spesies endemik yang ada di TNWK. Spesies-spesies tersebut merupakan spesies yang mendominasi pada hutan hujan dataran rendah di TNWK. Kondisi topografi TNWK yang relatif datar dan sedikit bergelombang dibagian timur dengan ketinggian $0-50$ $\mathrm{m}$ dpl dan termasuk dalam tipe iklim B dengan musim kemarau secara umum berlangsung selama dua bulan atau lebih, tumbuhan tersebut sangat sesuai untuk tumbuh di TNWK (Balai Taman Nasional Way Kambas, 2006).

Richard (1996) mengemukakan bahwa udara yang lembab dan suhu yang rendah memungkinkan pertumbuhan dari vegetasi berlimpah. Selain suhu, intensitas cahaya juga berpengaruh terhadap vegetasi. 
Di SPTN Wilayah III Kuala Penet Resort Margahayu tidak tiap jenis dapat bergenerasi, karena memungkinkan terjadi pergantian jenis yang mendominasi pada tingkat pertumbuhan. Pada beberapa jenis seperti bungur, joho, akasia, dan menggris tidak ditemukan permudaan tingkat semai, pancang maupun tiang, sehingga regenerasi pada jenis-jenis tersebut akan terhambat. Jenis yang memiliki regenerasi positif adalah jenis sonokeling, kelandri, puspa, berasan, laban, kopen, dan plangas. Dengan jumlah semai dan pancang mendominasi struktur pertumbuhan dan jenis yang memiliki kehadiran tingkat pertumbuhan yang lengkap.

\section{Struktur Tegakan}

\section{a. Struktur tegakan horizontal}

Struktur tegakan hutan dapat diartikan sebagai sebaran pohon per satuan luas dalam berbagai kelas diameternya (Meyer et al, 1961 dalam Heriyanto et al, 2007). Struktur tegakan horizontal berdasarkan kelas diameter yang ada di SPTN Wilayah III Kuala Penet Resort Margahayu, memiliki kerapatan pohon yang berbeda-beda. Spesies terbanyak terdapat pada kelas diameter $<10 \mathrm{~cm}$ dengan jumlah 811 batang/ha, kemudian semakin berkurang pada kelas diameter $10-<20 \mathrm{~cm}$ dengan jumlah 118 batang/ha, dan kerapatan pohon paling sedikit terdapat pada kelas diameter $>60 \mathrm{~cm}$ yaitu menggris.

Hal ini sesuai dengan penelitian yang dilakukan oleh Kusmana dan Susanti (2015) di Hutan Pendidikan Gunung Walat Sukabumi, Hidayat (2014) di Hutan Lindung Sesaot Kabupaten Lombok Barat Nusa Tenggara Barat dan Suwardi (2013) di Hutan Tropis Dataran Rendah, Ulu Gadut, Sumatera Barat menerangkan bahwa kerapatan pohon menurun secara eksponensial dari pohon berdiameter kecil berdiameter besar.

\section{b. Struktur tegakan vertikal}

Menurut Vickery (1984) yang dikutip oleh Indriyanto (2006) stratifikasi atau pelapisan tajuk merupakan susunan tetumbuhan secara vertikal di dalam suatu komunitas tumbuhan atau ekosistem hutan. Stratifikasi pada ekosistem hutan hujan tropis terkenal dan lengkap.

Menurut Indriyanto (2006) stratifikasi yang terdapat pada hutan hujan tropis dapat dibagi menjadi lima stratum berurutan dari atas ke bawah, yaitu.

a. Stratum A (A-storey) yaitu lapisan tajuk hutan paling atas yang dibentuk oleh pohon-pohon yang tingginya lebih dari $30 \mathrm{~m}$.

b. Stratum B (B-storey) yaitu lapisan tajuk kedua dari atas yang dibentuk oleh pohon-pohon yang tingginya mencapai $20-30 \mathrm{~m}$.

c. Stratum C (C-storey) yaitu lapisan tajuk ketiga dari atas yang dibentuk oleh pohon-pohon yang tingginya mencapai $4-20 \mathrm{~m}$.

d. Stratum D (D-storey) yaitu lapisan tajuk keempat dari atas yang dibentuk oleh spesies tumbuhan semak dan perdu yang tingginya $1-4 \mathrm{~m}$.

e. Stratum E (E-storey) yaitu tajuk paling bawah (lapisan kelima dari atas) yang dibentuk oleh spesies-spesies tumbuhan penutup tanah (ground cover) yang tingginya $0-1 \mathrm{~m}$.

Berdasarkan hasil penelitian diketahui bahwa struktur tegakan vertikal yang ditemukan di SPTN Wilayah III Kuala Penet Resort Margahayu yang memiliki jumlah spesies terbanyak yaitu pada stratum $\mathrm{C}$ dengan jumlah spesies sebesar 28 spesies, sedangkan untuk spesies terendah yaitu pada stratum B yaitu joho, dan pada stratum A tidak ditemukan jenis penyusunya, karena untuk mencapai stratum A dan stratum B sangat sulit. Hal ini terbukti dari sedikitnya pohon yang bisa mencapai statum A, keadaan ini disebabkan oleh untuk mencapai stratum A dibutuhkan waktu yang cukup lama dan persaingan yang cukup tinggi baik dari segi nutrisi, air, tanah maupun dalam cahaya (Kusmana dan Susanti, 2015). 
Indriyanto (2008) menjelaskan bahwa adanya tingkat stratum dikarenakan persaingan antar tumbuhan serta sifat toleransi spesies pohon terhadap radiasi matahari. Selain itu stratum juga menunjukkan kelas umur dari masing-masing vegetasi penyusun hutan.

Beberapa spesies yang menempati stratum C, stratum D dan stratum E adalah puspa, parutan, laban, plangas, kopen, dan berasan. Spesies-spesies tersebut merupakan spesies endemik di hutan hujan dataran rendah TNWK yang mendominansi struktur pertumbuhan dan jenis yang memiliki kehadiran tingkat pertumbuhan yang lengkap (Balai Taman Nasional Way Kambas, 2006).

Soerianegara dan Indrawan (1988) menyatakan bahwa di dalam masyarakat hutan, sebagai akibat persaingan, jenis-jenis tertentu lebih berkuasa (dominan) dari jenis yang lain. Pohon-pohon tinggi dari stratum (lapisan) teratas mengalahkan pohon-pohon yang lebih rendah, merupakan pohon yang mencirikan masyarakat hutan yang bersangkutan.

Klasifikasi pohon dapat didasarkan pada ukuran pohon atau posisi tajuk di dalam hutan. Berdasarkan posisi tajuknya klasifikasi pohon menurut Kraft dibedakan menjadi 5 kelas yaitu (Indriyanto, 2008).

1. Pohon dominan di SPTN Wilayah III Kuala Penet Resort Margahayu adalah sonokeling (Dalbergia latifolia) dengan rata-rata tinggi diatas $15 \mathrm{~m}$. Pohon sonokeling memiliki ukuran tinggi antara 20-40 m, kulitnya berwarna abu-abu kecoklatan, membujur halus dan agak sedikit pecah-pecah. Memiliki bentuk daun majemuk menyirip gasal yang berbentuk tumpul lebar serta berwarna hijau di sisi atasnya, sedangkan daun sisi bawah berwarna keabu-abuan. Bentuk tajuknya selebat berbentuk seperti kubah dan menggugurkan daun.

2. Pohon kodominan di SPTN Wilayah III Kuala Penet Resort Margahayu adalah pohon puspa (Schima wallichii). Walaupun tidak setinggi pohon dominan tetapi masih dapat cahaya dari atas meskipun cahaya dari samping terganggu oleh pohon dominan. Pohon yang selalu hijau ini, berukuran sedang hingga besar, mencapai tinggi lebih dari $40 \mathrm{~m}$ berdiameter $1,5 \mathrm{~m}$. Kulit batangnya berwarna coklat kemerahan atau coklat kelabu, sebelah dalam berwarna merah terang, daunnya tersebar dalam spiral, bertangkai sekitar 3 $\mathrm{mm}$, helai daun lonjong hingga jorong lebar $6-13 \times 3-5 \mathrm{~cm}$, tajuknya berbentuk bulat dengan daun mudanya yang berwarna merah jambu.

3. Pohon tengahan adalah pohon dengan bagian besar tajuk di bawah lapisan tajuk atau terjepit, menerima sebagian sinar matahari dari atas dan sebagian kecil atau tidak sama sekali dari samping, yang termasuk pohon tengahan yaitu sempu (Dillenia exelsa), tinggi hingga 40-50 m kulitnya halus sedikit retak-retak sering kali berwarna cokelat kemerahan atau cokelat keabuan. Daun-daun terletak dalam spiral, tunggal, bertepi rata, menggelombang, atau bergigI, bertulang daun menonjol, tangkai daun sering bersayap. Pohon sempu di SPTN Wilayah III Kuala Penet Resort Margahayu memiliki tinggi dibawah $20 \mathrm{~m}$.

4. Pohon tertekan adalah pohon dengan tajuk dinaungi pohon besar dan tidak menerima sinar matahari sepenuhnya, baik dari atas maupun dari samping, yang termasuk pohon tertekan yaitu laban pohon tinggi sampai 2-15 meter, hingga $40 \mathrm{~cm}$ (diameter setinggi dada). Pohon ini mempunyai banyak cabang yang tidak lurus atau bengkok serta tidak teratur. Kayunya cukup keras serta padat, seratnya lurus, warnanya selang-seling yaitu cokelat kuning dan cokelat pudar tua. Bentuk daun bulat telur sampai lonjong atau elip, dan meruncing ke ujung dan pangkal daun. Tinggi pohon laban di SPTN Wilayah III Kuala Penet Resort Margahayu rata-rata di bawah $15 \mathrm{~m}$.

\section{Permudaan Alam}

Menurut Direktorat Jenderal Pengusahaan Hutan (1993) penyebaran permudaan baik pada tingkat semai, pancang, maupun tiang berbagai jenis pohon tergantung pada jenis 
individu pada fase pohon tersebut beradaptasi dengan lingkungannya. Permudaan alam adalah pengadaan tegakan baru dalam peremajaan hutan secara alami, tanpa dilakukan campur tangan manusia.

Permudaan alam terdiri dari:

1. Permudaan tingkat semai adalah permudaan yang tingginya $0,3 \mathrm{~m}-1,5 \mathrm{~m}$.

2. Permudaan tingkat pancang adalah permudaan yang berukuran tinggi lebih dari $1,5 \mathrm{~m}$ dengan diameter kurang dari $10 \mathrm{~cm}$.

3. Permudaan tingkat tiang adalah pohon muda yang berdiameter $10-19 \mathrm{~cm}$.

Permudaan alam di SPTN Wilayah III Kuala Penet Resort Margahayu berdasarkan kerapatan tegakan permudaannya, kerapatan terbanyak pada setiap fase pertumbuhan di SPTN Wilayah III Kuala Penet Resort Margahayu adalah fase semai, yang memiliki jumlah sebesar 483 batang, diikuti pancang sebesar 310 batang, dan tiang sebesar 126 batang. Permudaan tersebut umum terjadi pada hutan alam yang kerapatan jenis tertingginya adalah fase semai (Kusmana dan Susanti, 2015). Karena jumlah semai sangat berlimpah dibandingkan dengan pancang, tiang, dan pohon, sehingga kondisi permudaan alam di SPTN Wilayah III Kuala Penet Resort Margahayu kerapatan tegakannya jika dilihat dari kelas permudaannya maka akan membentuk kurva huruf "J" terbalik. Menurut Muller-Dumbois and Ellenberg (1974) kondisi atau gambaran tersebut merupakan ciri umum permudaan alami yang berlangsung dengan normal.

Hal ini sesuai dengan hasil penelitian Harianja (2012) pada Kawasan Hutan Palanro menunjukkan bahwa potensi permudaan eboni pada tingkat semai lebih besar dari pada pancang dan tiang. Perbedaan jumlah individu pada tingkat semai sampai tiang sangat mencolok yaitu jumlah semai sangat berlimpah dibandingkan dengan pancang dan tiang. Keadaan ini dapat dilihat dari histogram distribusi kelas permudaan eboni yang berbentuk kurva "J" terbalik. Terbentuknya kurva "J" terbalik karena dalam proses pertumbuhan eboni memerlukan rentang waktu cukup panjang dan dalam proses tersebut terjadi persaingan antara sesama eboni dan jenis lain dalam hal unsur hara, air, ruang tumbuh dan cahaya sehingga ada individu yang terkalahkan kemudian mengalami kematian dan sedikit yang bertahan hidup (Harianja, 2012).

Menurut (Meyer, 1952) kondisi hutan semacam ini akan menjamin kelestarian hutan di masa yang akan datang karena jumlah individu permudaan semai jauh lebih banyak dari pada jumlah individu pohon dewasa, dimana stok permudaan tersebut sangat penting untuk memelihara kemampuan regenerasi hutan bagi terbentuknya hutan klimaks, namun konsekuensi dari fenomena ini adalah akan hilangnya beberapa jenis yang jumlah individunya relatif lebih sedikit, dan timbulnya jenis-jenis dominan dari jenis-jenis pohon yang regenerasinya cukup melimpah.

Berdasarkan hasil penelitian, kondisi permudaan alam di SPTN Wilayah III Kuala penet Resort Margahayu dapat dilihat pada Gambar 8 berikut.

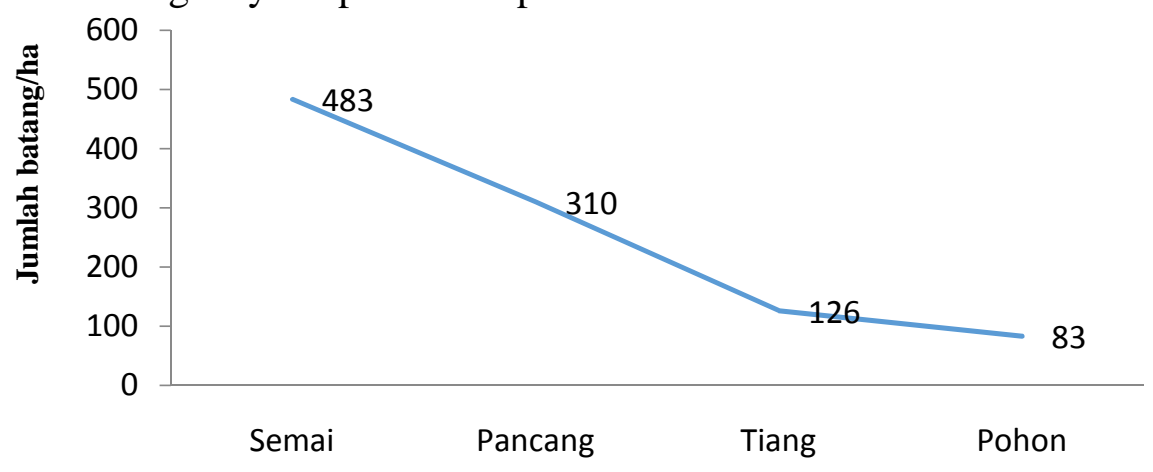

Fase Pertumbuhan

Gambar 8. Kerapatan tegakan pada setiap fase pertumbuhan. 


\section{SIMPULAN}

Berdasarkan hasil penelitian, diperoleh simpulan sebagai berikut.

1. Terdapat 32 spesies tumbuhan di SPTN Wilayah III Kuala Penet Resort Margahayu, dengan INP yang menunjukkan bahwa jenis berasan, kopen, puspa, sempu, sonokeling, dan tiga urat mendominasi dalam kawasan, sedangkan jenis belimbingan, bungur, keteja, mahoni, tutup, dan waru memiliki tingkat penguasaan paling rendah.

2. Struktur tegakan secara horizontal menunjukkan bahwa tegakan didominansi oleh tumbuhan dengan diameter $<10 \mathrm{~cm}$ dan semakin berkurang pada diameter $10-<20 \mathrm{~cm}$ sampai $>60 \mathrm{~cm}$. Sedangkan struktur tegakan vertikal menunjukkan bahwa tegakan didominansi oleh stratum C sebanyak 28 jenis, diikuti stratum D (22) jenis, stratum E (18) jenis, dan stratum B satu jenis.

3. Kondisi permudaan alam di SPTN Wilayah III Kuala Penet Resort Margahayu menunjukkan kondisi hutan normal, karena tingkat kerapatan didominansi oleh fase semai, diikuti pancang, tiang dan pohon dengan bentuk kurva menyerupai huruf "J" terbalik. 


\section{DAFTAR PUSTAKA}

Balai Taman Nasional Way Kambas. 2006. Zonasi Taman Nasional Way Kambas. Buku. Taman Nasional Way Kambas. Lampung Timur. 13 p.

Direktorat Jendral Pengusahaan Hutan. 1993. Pedoman dan Petunjuk Teknis Tebang Pilih Tananam Indonesia (TPTI) Pada Hutan Alam Daratan. Departemen Kehutanan. Jakarta.

Fachrul, M. F. 2007. Metode Sampling Bioekologi. Buku. Bumi Aksara. Jakarta. 208 p.

Harianja, H. C. 2012. Potensi Permudaan Alam Eboni (Diospyros celebica bakh.) di Kawasan Hutan Palanro Kecamatan Cenrana Kabupaten Maros. Skripsi. Universitas Hasanuddin. Makassar. 53 p.

Heriyanto, N.M. dan R. Garsetiasih. 2007. Komposisi jenis dan struktur tegakan hutan rawa gambut di kelompok hutan sungai belayan-sungai kedang kepala, Kabupaten Kutai, Kalimantan Timur. Info Hutan IV (2): 213-221.

Hidayat, S. 2014. Kondisi vegetasi hutan lindung Sesaot, Kabupaten Lombok Barat, Nusa Tenggara Barat, sebagai informasi dasar pengelolaan kawasan. Jurnal Penelitian Kehutanan Wallacaea. 3 (2): 97-105.

Indriyanto. 2006. Ekologi Hutan. Buku. Bumi Aksara. Jakarta. 198 p. 2008. Pengantar Budidaya Hutan. Buku. Bumi Aksara. Jakarta. 233 p.

Kusmana, C. dan S. Susanti. 2015. Komposisi dan struktur tegakan hutan alam di Hutan Pendidikan Gunung Walat, Sukabumi. Jurnal Silvikultur Tropika. 5 (3): 210-217.

Meyer, H.A., A.B. Recknagel and D.D. Stevenson. 1952. Forest Management Second Edition. Buku. The Ronald Press Company. New York. 290 p.

Mueller-Dombois, D. and H. Ellenberg 1974. Aims and Methods of Vegetation Ecology. Buku. John Wiley and Sons. New York. 547 p.

Odum, E. P. 1994. Dasar-Dasar Ekologi Edisi Ketiga. (Diterjemahkan oleh Tjahjono Samingan dan B. Srigandono). Buku. Gadjah Mada University Press. Yogyakarta. 697 p.

Pratiwi, Y.Y. 2014. Komposisi dan Struktur Tegakan Zona Pemanfaatan Terbatas SPTN 1 Way Kanan, Taman Nasional Way Kambas. Skripsi. Universitas Lampung. Lampung. $63 \mathrm{p}$.

Richards, P. W. 1966. The Tropical Rain Forest and Ecological Study. Buku. Cambridge University Press. New York. 575 p.

Soerianegara, I. dan A. Indrawan. 1988. Ekologi Hutan Indonesia. Buku. Institut Pertanian Bogor. Bogor. 123 p.

Bogor. Bogor. $126 \mathrm{p}$. 1998. Ekologi Hutan Indonesia. Buku. Institut Pertanian

Suwardi, A. B., E. Mukhtar dan S. Syamsuardi. 2013. Komposisi jenis dan cadangan karbon di hutan tropis dataran rendah, Ulu Gadut, Sumatera Barat. Berita Biologi. 12 (2): 169176. 